\title{
Idiopathic scoliosis surgical treatment. Results in Mexico's National Rehabilitation Institute. 24-month follow-up
}

Tratamiento quirúrgico de la escoliosis idiopática del adolescente. Resultados en el Instituto Nacional de Rehabilitación de México. Seguimiento mínimo de 24 meses

\section{Barón Zárate-Kalfópulos ${ }^{1 *}$, Héctor R. Martínez-Ríos², Francisco López-Meléndez,} Carla L. García-Ramos ${ }^{1}$, Luis M. Rosales-Olivarez ${ }^{1}$ and Alejandro A. Reyes-Sánchez ${ }^{1}$

${ }^{1}$ Division of Spine Surgery; ${ }^{2}$ Division of Orthopedics. Instituto Nacional de Rehabilitación, Mexico City, Mexico

\begin{abstract}
\end{abstract}
Background: Adolescent's idiopathic scoliosis is defined as a three-dimensional deformity of the spine, which occurs between 10 and 18-year-old, has a spinal curvature $>10^{\circ}$ in the coronal plane. This deformity affects $2-3 \%$ of the general population, however, only $10 \%$ of the total will require surgery at some point. The method of choice for management is the use of $\bar{p}$ edicle screws and rods derotational. Objective: To perform a descriptive analysis of patients who received surgical treatment in our institute with pedicle screws and rods. Methods: This is an observational, retrospective, analytical, open study, nonprobability sampling, in which patients requiring surgical treatment at our institute between 2012 and 2013 were included the deformities were stratified according to the classification of Lenke. The angle of deformity correction, instrumented levels, amount of bleeding, presence of complications were the variables analyzed. Results: Lenke classifying mostly IBN, Moe Nash III, an average of $59.4^{\circ} \mathrm{Cobb}$ and kyphosis of 47.8. On average it was followed patients for 35.84 months, detecting an increase $2.28^{\circ}$ coronal curvature and sagittal curvature increase of $2.8^{\circ}$. Conclusion: Comparing these results and world literature concluded that the treatment of adolescent's idiopathic scoliosis is a safe and reproducible method that provides greater biomechanical and biological advantage over the use of mixed instrumentation used previously.

KEY WORDS: Adolescent idiopathic scoliosis. Pedicle screws. Spinal fusion. Treatment outcome.

\section{Resumen}

Antecedentes: La escoliosis idiopática del adolescente se define como una deformidad tridimensional de la columna vertébral que se presenta entre los 10 y los 18 años, y que se manifiesta con una curvatura vertebral en el plano coronal mayor de $10^{\circ}$. Esta deformidad afecta al 2-3\% de la población general, pero solo el 10\% del total requerirá en algún momento tratamiento quirúrgico. El método de elección para el manejo es el uso de tornillos transpediculares y barras desrotadoras. Objetivo: Realizar un análisis descriptivo de los pacientes que recibieron manejo quirúrgico en nuestro instituto con torhillos transpediculares y barras. Método: Se trata de un estudio observacional, retrospectivo, analítico, abierto, de muestreo ho probabilístico, en el que se incluyeron los pacientes tratados con manejo quirúrgico entre 2012 y 2013. Las deformidades se estratificaron de acuerdo con la clasificación de Lenke. El ángulo de corrección de la deformidad, los niveles instrumentados, el sangrado transquirúrgico y la presencia de complicaciones fueron las variables analizadas. Resultados: La mayoría de los pacientes presentaron curvas Lenke IBN, Nash Moe III, Cobb un promedio de 59.4 y cifosis de 47.8. En promedio se siguió

\author{
Correspondence: \\ *Barón Zárate-Kalfópulos \\ Calzada México-Xochimilco 289, \\ Col. Arenal de Guadalupe, Del. Tlalpan \\ C.P.14389, Mexico City, Mexico \\ E-mail: baronzk@ hotmail.com
}

Date of reception: 04-12-2017

Date of acceptance: 16-06-2018

DOI: $10.24875 / C I R U E . M 18000059$
Cir Cir. 2018;86:343-348

Contents available at PubMed www.cirugiaycirujanos.com 
a los pacientes por 35.84 meses, detectando un aumento de la curvatura coronal de $2.28^{\circ}$ y un aumento de la curvatura sagital de 2.8 . Conclusión: Al comparar estos resultados y la literatura mundial se concluyó que el tratamiento de la escoliosis idiopática del adolescente es un método seguro y reproducible que ofrece una mayor ventaja biomecánica y biològica sobre el uso de instrumentación mixta utilizada anteriormente.

PALABRAS CLAVE: Escoliosis idiopática del adolescente. Tornillos transpediculares. Artrodesis de columna vertébral. Resultados de tratamiento.

\section{Introduction}

Adolescent idiopathic scoliosis (AIS) is a deformity of the spine in the coronal, axial and sagittal planes, with a curvature greater than $10^{\circ}$ in the coronal plane, which affects patients aged between 10 and 18 years, with an impact on the psychological functional, and cosmetic states'.

Classic presentation ( $80 \%$ of the population) is that of a female patient with a thoracic curvature greater than $20^{\circ}$, rotational deformity and hypokyphosis ${ }^{1}$. It is a relatively common pathology, which affects $2-3 \%$ of the population, but only $10 \%$ of affected individuals will require surgical treatment at some point ${ }^{2}$.

Among the described theories, the genetic factor has been associated as the probable origin of this pathology, without this being conclusive. ${ }^{3}$ Due to the large variability of presentation, influenced by factors such as gender, age of onset, skeletal growth peak, size and type of curve, its description and study are difficcult'.

King was the first one to establish an anatomomorphological classification of thoracic deformities, but did not take lumbar curvatures into account and, in addition, subsequent studies report high inter-observer and intra-observer variability ${ }^{4,5}$. The most common classification currently used is the one described by Lenke, designed for surgical planning. With this classification, less limitations are reported than with King's classification, and it is useful for comparing different treatments or single treatments; it has less intraobserver and inter-observer variability, and provides higher certainty in the development of a surgical plan ${ }^{6}$.

If spine deformity has a curvature greater than $50^{\circ}$, respiratory and cardiac function are compromised, and the patient reports chronic pain and fatigue for carrying out daily life activities?

AIS surgical indications are a curvature greater than $50^{\circ}$ in the coronal plane, a curvature greater than $40^{\circ}$ in a patient with skeletal immaturity, progression of the condition despite conservative treatment with the use of corrective bracing and a deformity that is unacceptable for the patient ${ }^{8}$.
The goals of surgical treatment with pedicle screews and rods are obtaining a significant, functional and esthetic correction, achieving stable vertebral arthrodesis, lower non-union rates (allows performing osteotomies), preventing recurrence and correction toss, and allowing patient early postoperative mobility ${ }_{\frac{C}{C}}^{1}$

In 1962, Harrington described the use of de-rotation rods for the management of scoliosis and reported poor control of the sagittal deformity correction ${ }^{9-11}$. In the 1980s, the use of hooks and sublaminar wires wैas introduced by Cotrel Dubousset and Luque, respectively; these systems allowed an improvement in the control of sagittal and coronal correction, in addition to patient early mobilization ${ }^{10,12}$.

In 1963, Roy-Camille introduced pedicle scrêws with the purpose to treat pathologies located onfy in the lumbar region ${ }^{10,13}$. However, their use was recommended only under specific circumstances, because of the danger (vascular, nervous and visceral initry) and the difficulty the placement of the screw entailed due to the complicated pedicular morphology, which undergoes an anatomical alteration in terms of volame (varying from 2.5 to $12 \mathrm{~mm}$ in width and from 9.6 to $16 \mathrm{~mm}$ in height) and direction (orientation in the axial, sagittal and coronal plane), affected by the vertebral level, and patient age and height ${ }^{1,5}$. To decrease the difficulty in the placement of the pedicle screws, \$actors that increase safety are taken into account, such as the structural anatomical factor and the pedicular medial wall, which is stronger than the lateral wäll ${ }^{4}$. Gerztbein and Robbins ${ }^{15}$ described the safety zone, which covers $4 \mathrm{~mm}$ added to the pedicle medial border, corresponding to $2 \mathrm{~mm}$ of epidural space and $2 \mathrm{~mm}$ of subaracnoid space. This same concept $\bar{w}$ was used for the placement of sublaminar hooks, since these encompass an area of 2-3 $\mathrm{mm}$ of this safety $z o n e^{16}$. However, the purpose of the description ofthe safety zone is not using it in its entirety, since placement is acceptable when the screw exceeds the medial cortical wall by $2 \mathrm{~mm}^{1,16}$.

Currently, hook and wire systems have fallen into disuse due to the implementation and subsequent demonstration of the advantages of treatment with pedicle 

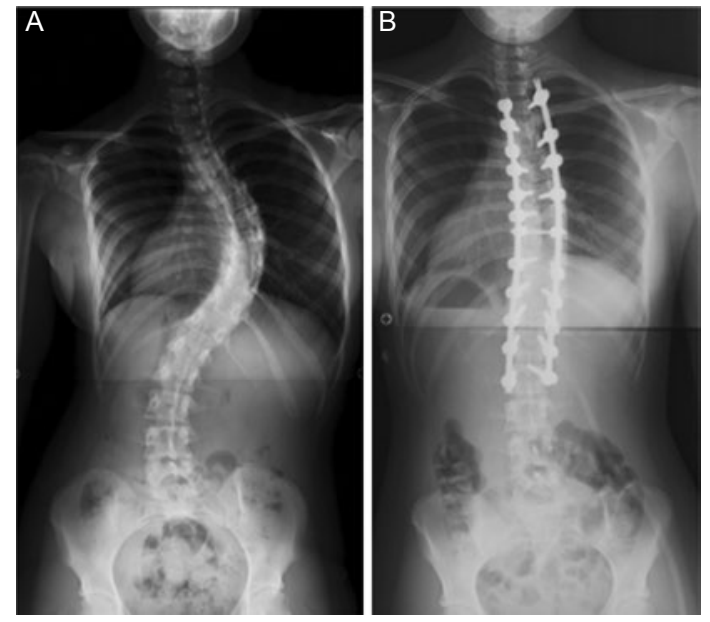

Figure 1. Anteroposterior, pre-surgical (A) and post-surgical (B) X-rays of a patient with adolescent idiopathic scoliosis. A post-surgical correction of $54^{\circ}$ is observed at the coronal plane with the use of pedicle screws.

screws and rods ${ }^{1}$. Placement of pedicle screws and rods corrects the deformity in all three anatomical columns, preventing the crankshaft effect, decreasing the number of instrumented levels and offering a better correction of the deformity ${ }^{1,17}$ (Fig. 1).

Suk et al. ${ }^{17}$ are pioneers in the use of pedicle screws in all pedicles, demonstrating their safety in the treatment of AIS. They reported their results with a study that included 462 patients (with 4,604 screws being placed), with malposition observed in 48 patients (1.5\% of total screws), out of which only four screws exceeded the medial cortical wall, without any neurological, vascular or visceral injury being reported. They demonstrated that, with appropriate training and experience, the placement of the screws is not influenced by overall vertebral deformity. Kuklo et al. ${ }^{4}$ reported the placement of screws in 20 patients with an overall curvature of $100.2^{\circ}$, with an accuracy of $96.3 \%$ in the positioning of the screws, without neurovascular or visceral injuries being reported.

AIS treatment evolution with the use of pedicle screws and rods demonstrates biomechanical superiority, with lower rates of complications, improving the correction of patient's radiographic and clinical deformity, in comparison with the techniques that were previously used in our institute 1 .

To date, there are no descriptive studies in Mexico that allow us knowing the radiographic, clinical and functional results of AIS treatment with pedicle screws and de-rotation rods. Knowing the caseload of surgically-treated AIS patients and the prevalence of complications is sought, as well as comparing the results obtained with previously used techniques in our institute and other specialized centers, in order to know the percentage of correction, and describe and analyze other variables (bleeding, surgical time and instrumented levels).

\section{Method}

The medical records of patients aged between 13and 18 years, diagnosed with AIS, treated with surgical management using pedicle screws and de-rotation rê $\mathrm{ds}$, operated in our institute between 2010 and 2013, with follow-up of at least 2 years, and who had had complete clinical and imaging records, were reviewed.

Data collection was carried out by two orthopedists who were not directly involved with patients' surgical procedures. Statistical data were analyzed with the SPSS program (version 21). Analysis was performed with descriptive statistics for frequencies, percentages, means and standard deviations. A Kolmogorov-Smimnov test was carried out to verify the normality of the sample, and a t-test for paired (related) samples was used for continuous variables, in order to find out the differences. An analysis of variance (ANOVA) test was carried out to detect correction differences between different Lenke classification groups with regard to correction percentage. All statistical tests were crossed, and a $p$-value $<0.05$, with its $95 \%$ confidence interval (Cl) was considered statistically significant.

\section{Results}

Forty-three AIS-diagnosed patients were identified, out of which 25 met the inclusion criteria for this stưdy. Two males and 23 females were included (92\%), With a normal age distribution of 17 years ( \pm 2.79 years). Twenty-two patients had a reducible deformity and three had an irreducible deformity; only two patients had neurological deficit (ASIA D). They were claassified, according to Lenke, based on the curve type: type I curvature in 14 patients (56\%), type III in 8, type II in 4 and type $\mathrm{VI}$ in 2. According the lumbar modifier, there were 11 patients with lumbar modifier $B$ (44\%), 9 with lumbar modifier $C(36 \%)$ and 5 with Fumbar modifier A. According to the sagittal modifier, there were 15 patients $(60 \%)$ with neutral thoracic kyphosis $\left(10-40^{\circ}\right), 8$ patients with increased kyphosis (greater than $40^{\circ}$ ) and 2 patients with decreased $\mathrm{ky}$ phosis (less than $10^{\circ}$ ). Coronal deformity was measured with Cobb's method, with an average of $60.8^{\circ}$ being found, with a range of 38 to $113^{\circ}$ (standard deviation 15.87), as well as an average kyphosis of 


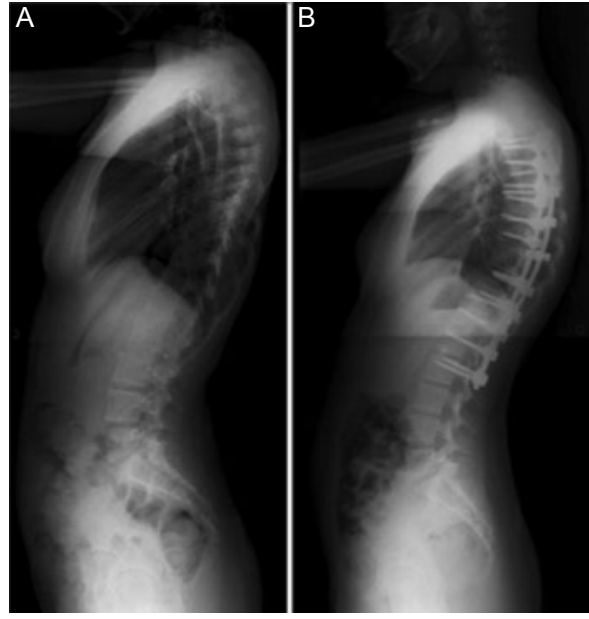

Figure 2. Lateral pre-surgical (A) and post-surgical (B) X-ray of a patient diagnosed with scoliosis. The pedicle screws can be observed in the thoracolumbar column.

$47.8^{\circ}$, ranging from 10 to $90^{\circ}$. Average compromised levels was 9.92 (range: 6-14). Apical vertebral rotation was also classified by means of Nash Moe's scale, with 14 with subjects being found with a type-3 deformity, 10 with type-2 deformity, and one with type-4 deformity.

After completing the pre-surgical protocol, all $25 \mathrm{pa}$ tients underwent the surgical procedure. Out of them, 23 were posteriorly approached (92\%) and two had an anterior and posterior approach, with 350 to $4,500 \mathrm{cc}$ bleeding (average 1,146 cc), an average surgical time of 320.72 minutes (ranging from 210 to 480 minutes) and with an average of 10.88 instrumented levels (range: 4-15).

Six patients suffered trans-surgical and immediate postoperative complications (infection, hypovolemia, dural injury, spinal cord injury, rod cutting, pleuropulmonary injury), but only three required revision surgery (infection, prolonged surgical time). Average hospital length of stay was 8.88 days ( \pm 7.06 days) (Fig. 2).

After the surgical event, imaging studies were carried out, with an average percentage coronal deformity reduction of $64 \%\left(21.6 \pm 11.66^{\circ}\right)$ and sagittal deformity reduction of $66.71 \%\left(33.7 \pm 16.6^{\circ}\right)$ being found, with an average Nash Moe rotational correction of 2 .

Patients were followed for at least 24 months (average of $35.84 \pm 11.4$ months) with interrogation, physical examination and imaging studies (anteroposterior and lateral panoramic radiograph of the spine), with a minimal increase of $2.28^{\circ}\left(23.9 \pm 12.57^{\circ}\right)$ being observed in coronal curvature. A t-test for related samples was performed to look for statistical significance, with a pvalue $<0.0001$ being found for the Cobb angle presurgically and at the end of the follow-up, with no difference being observed between the immediate post-surgical and follow-up periods ( $p>0.05$ ).

An increase in sagittal curvature of $2.8^{\circ}$ (average of $35.84 \pm 16.69^{\circ}$ ) was reported, with a $p$-value $<0 . \overline{0} 01$, with a difference being found between the immediate postoperative period and the follow-up conclusion $(p=0.017)$.

During follow-up, rupture of the rod was reported in one patient, which until the time of the study did not require revision surgery. All patients had the SRS-22 questionnaire applied, where an average result in the pain dimension of 2.8, 3.8 for self-image, 3 for fonction, 3 for mental health and 3.5 for surgical satisfaction were recorded, in a 1-to-5 scale.

\section{Discussion}

There are few reports in the literature on AIS treatment with pedicle screws and rods with long-term follow-up, with a minimum reduction loss being found in most series with a follow-up no longer than 24 months'.

Our series, composed of $76 \%$ of female patients, agrees with Westrick and Ward report ${ }^{2}$, who published a series of 99 patients operated with the referred technique with an incidence of the same gender of $79 \%$. An epidemiological review concludes that AIS total incidence (in operated patients and in those whoreceive conservative treatment) is much higher in females than in males ${ }^{8}$.

Hwang et al. ${ }^{1}$ conducted a multicenter study in 2012, and recorded the type of deformity according to Eenke, with $54.4 \%$ being found to have type I, with an average main curvature of $54.7^{\circ}$ and a $22.3^{\circ} \mathrm{kyph} \overline{\mathrm{o}} \mathrm{sis}$ (measured from T5 to T12). Conversely, in our documentation we reported $56 \%$ of type I coronal deformity, an average main curve of $59.4^{\circ}$ and kyphosis of $47.8^{\circ}$, with the latter point especially differing. When analyzing this result, we observed how the small size of the study affects, since having patients with a-kyphosis deformity of up to $90^{\circ}$ skews the mean.

We studied apical vertebral rotation using the Nash Moe scale, with 14 patients being reported with a type III deformity, 10 with a type II deformity and-one with a type IV deformity. Kuklo et al. ${ }^{4}$ carried out a study involving 19 Lenke I, Nash Moe III patients. All of them had a radiographic imaging study performed, which was compared against a computed tomography (CT) scan; in all 38 studies was apical vertebral retation measured with the Nash Moe method, with a trend towards an increase in the Nash Moe seore 
being observed with the radiological study. The authors referred that even grade 0 determined with a radiographic technique has some degree of rotation that is demonstrated by CT. However, the cost of performing a CT scan only for measuring axial rotation outweighs the benefit, since it exposes the patient to a high degree of radiation, in addition to entailing a high economic cost, without making any difference in the pre-surgical plan carried out with radiological imaging and physical examination ${ }^{4}$.

Kim et al. ${ }^{18}$ conducted a retrospective study with 29 patients, where they recorded a surgical time average of 347 minutes, 27 minutes more than the time reported in our study (320.72 minutes). We recorded an average blood loss of $1,146 \mathrm{cc}$ versus a blood loss reported by $\mathrm{Kim}$ et $\mathrm{al}^{18}$ of $961 \mathrm{cc}$, with an average difference of $185 \mathrm{cc}$. When average bleeding elevation was analyzed, patients with larger volume of blood loss were observed to be those with surgeries of longer surgical time and, therefore, longer anesthetic time. Due to the small sample size, the increase in bleeding volume average skews our mean.

Lehman et al. ${ }^{3}$ report an average of fused levels of 10 , while in our study we reported 9.92 fused levels on average. A 2005 study by Suk et al. ${ }^{5}$ found that the use of instrumentation with pedicle screws decreases the number of fused levels in comparison with the use of hybrid fixation, with similar results.

In our series, a rate of complications of $24 \%$ was reported, while the complication rate reported in the world literature ranges from 4.4 to $51 \%{ }^{1,3}$. The most important step to avoid complications is the placement of the pedicle screws; a long learning curve is required even for a highly experienced surgeon ${ }^{5}$, and has a significant influence on the large variability in terms of reported complications, such as spinal cord injury, bleeding, dislodgement and fractures.

Suk et al. ${ }^{5}$ carried out a study with 203 AIS-diagnosed patients treated with pedicle screws and rods, and concluded that this type of instrumentation demonstrates great biomechanical advantages over other forms of vertebral instrumentation, by correcting the deformity and maintaining the correction.

At 2 years of follow-up, a loss of coronal deformity reduction of $2.28^{\circ}$ was found and a loss of sagittal curvature reduction of $2.8^{\circ}$, in comparison with a 2-year follow-up carried out by Hwang, et al. ${ }^{1}$ with a coronal reduction loss of $2.8^{\circ}$, with no kyphosis deformity loss.

Suk et al. ${ }^{5}$ reported their results with a minimum follow-up of 5 years, with a loss of coronal correction of $3 \%$. Di Silvestre et al. ${ }^{19}$ compared pedicle screw

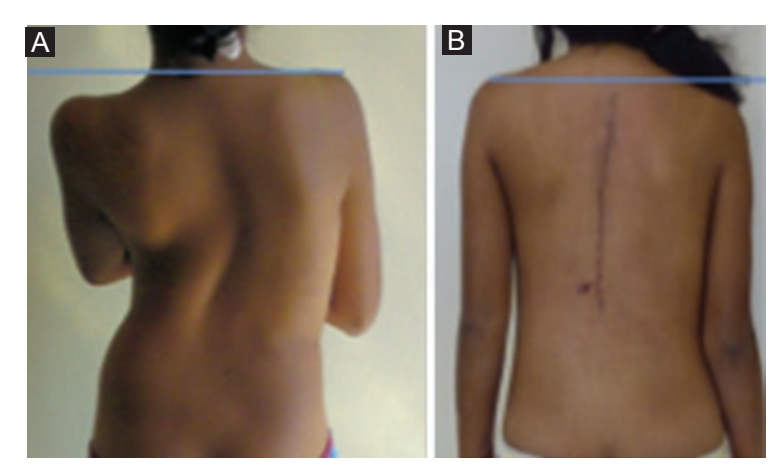

Figure 3. Clinical pre-surgical (A) and post-surgical (B) image a patient undergoing management with pedicle screws and rods. Correction of the deformity, adequate coronal alignment and shoulder and hip symmetry are observed.

instrumentation with hybrid instrumentation, with a follow-up of 6.7 years, and found better maintenance of deformity correction by using pedicle screws ànd rods. They observed a correction loss of $11.3^{\circ}$ with the use of hybrid instrumentation versus a correction foss of $1.9^{\circ}$ using pedicle screws. This way, long-term biomechanical superiority of the use of rods and pedicle screws is explained ${ }^{19}$.

A follow-up of patient clinical status was carriedout using the SRS-22 scale, with an overall result of $75 \%$ being found. Lehman et al. ${ }^{3}$, in a series of 114 patients, reported an overall result of $83.6 \% 3 . \ln 2004$, Bago et al. ${ }^{20}$ conducted a study for translation yairdation and a cultural validation of the SRS-22 questionnaire, which included 175 patients (152 females and 23 males), demonstrating that the Spanish versio $\hat{A}$ of the SRS-22 questionnaire is valid, with an excelfent reproduction of all items, and is equivalent and adiustable for clinical research (Fig. 3).

In 2007, Rosales-Olivarez et al. ${ }^{21}$ carried out adescriptive study of the National Rehabilitation Instifute (INR - Instituto Nacional de Rehabilitación) histöical records, where they included 120 patients (45 males and 75 females) diagnosed with congenital scoliesis, childhood idiopathic scoliosis, juvenile idiopathic scoliosis and AIS (25\%), with an average age of 12 years, treated with a posterior (54\%), anterior and mixed approach, using mixed techniques with Luque type d, II and III instrumentation (63\%). In said study, a presurgical curve of $55.58^{\circ}$ is described, while in the analyzed sample we obtained an initial curve of 60.8 in the previous study, a coronal correction average of $25.92 \%$ was reported, which represents $38.8 \%$ Tess than the correction assessed in our current study (64\%). They had a complication rate of $17 \%$ versus a rate of $24 \%$ reported in this study, perhaps because of the larger correction of the curve (14.47 vs. $\left.39.12^{\circ}\right)$, as 
well as due to the severity of the cases, in addition to the fact that the use of pedicle screws per se implies a higher volume of complications; however an incidence of spinal cord injury of $5 \%$ was reported, similar to the $4 \%$ in our report.

Pedicle screws current use at the INR for vertebral deformity correction offers greater biomechanical advantage over the previously used mixed instrumentation. By instrumenting the three anatomical columns of the vertebral body, the deformity is corrected and the correction maintained more effectively than with mixed instrumentation, thus lowering the rate of complications, bleeding and the number of instrumented levels ${ }^{5}$.

\section{Conclusions}

- AIS treatment with pedicle screws and rods is safe and effective to correct scoliotic deformity and maintain the correction.

- Current use of pedicle screws in our institute offers advantages over the use of previously used hybrid instrumentation for the correction of vertebral deformity in AIS, offering a greater biomechanical advantage and lowering the rate of complications, bleeding and the number of instrumented levels.

\section{Funding}

The authors declare that they have no funding source.

\section{Conflicts of interests}

The authors declare that there are no conflicts of interest.

\section{Ethical disclosures}

Protection of people and animals. The authors declare that no experiments have been carried out on humans or animals for this investigation.

Confidentiality of data. The authors declare that they have followed the protocols of their work center on the publication of patient data.

Right to privacy and informed consent. The authors have obtained informed consent of the patients and/or subjects referred to in the article. This document is in possession of the corresponding author.

\section{References}

1. Hwang SW, Samdani AF, Marks M, Bastrom T, Garg H, Lonner Bèt al. Five-year clinical and radiographic outcomes using pedicle screw only constructs in the treatment of adolescent idiopathic scoliosis. EurSpine J. 2013;22:1292-9.

2. Westrick ER, Ward WT. Adolescent idiopathic scoliosis: 5-year to 20=year evidence-based surgical results. J Pediatr Orthop. 2011;31(1 Suppl):S61-8.

3. Lehman RA Jr, Lenke LG, Keeler KA, Kim YJ, Buchowski JM, Cheh G, et al. Operative treatment of adolescent idiopathic scoliosis with posterior pedicle screw-only constructs: minimum three-year follow-up of one hundred fourteen cases. Spine (Phila Pa 1976). 2008;33:1598-604. 으

4. Kuklo TR, Potter BK, Lenke LG. Vertebral rotation and thoracic tersion in adolescent idiopathic scoliosis: what is the best radiographic correlate? J Spinal Disord Tech. 2005;18:139-47.

5. Suk SI, Lee SM, Chung ER, Kim JH, Kim SS. Selective thoracic fusion with segmental pedicle screw fixation in the treatment of thoracic idiopathic-scoliosis: more than 5-year follow-up. Spine (Phila Pa 1976). 2005;30:1602-9.

6. Danielsson AJ, Nachemson AL. Back pain and function 23 years after fusion for adolescent idiopathic scoliosis: a case-control study-part II. Spine (Phila Pa 1976). 2003;28:E373-83.

7. Kim YJ, Lenke LG, Kim J, Bridwell KH, Cho SK, Cheh G, et al. Comparative analysis of pedicle screw versus hybrid instrumentation in posterior spinal fusion of adolescent idiopathic scoliosis. Spine (Phila Pa 1976). 2006;31:291-8.

8. Asher MA, Burton DC. Adolescent idiopathic scoliosis: natural history and long-term treatment effects. Scoliosis. 2006;1:2.

9. Cochran T, Irstam L, Nachemson A. Long-term anatomic and functional changes in patients with adolescent idiopathic scoliosis treated by $\mathrm{Ha}$ rrington rod fusion. Spine (Phila Pa 1976). 1983;8:576-84.

10. Boos N, Aebi M. Spinal disorders. Fundamentals of diagnosis and treatment. En: Gruber P, Boeni T, editores. History of spinal disorders. Berlin, Heidelberg: Springer-Verlag; 2008. p.29-37.

11. Dobbs MB, Lenke LG, Kim YJ, Kamath G, Peelle MW, Bridwêll KH. Selective posterior thoracic fusions for adolescent idiopathic scoliosis: comparison of hooks versus pedicle screws. Spine (Phila Pa 1976). 2006;31:2400-4.

12. Ecker ML, Betz RR, Trent PS, Mahboubi S, Mesgarzadeh M, Bonakdapour A, et al. Computer tomography evaluation of Cotrel-Dubousset instrumentation in idiopathic scoliosis. Spine (Phila Pa 1976). 1988;13:1141-4.

13. Suk SI, Lee SM, Chung ER, Kim JH, Kim WJ, Sohn HM. Determination of distal fusion level with segmental pedicle screw fixation in single thoracic idiopathic scoliosis. Spine (Phila Pa 1976). 2003;28:484-91.

14. Abul-Kasim K, Ohlin A, Strömbeck A, Maly P, Sundgren PC. Radiological and clinical outcome of screw placement in adolescent idiopathic scoliosis: evaluation with low-dose computed tomography. Eur Spine J. 2010;19:96-104

15. Gertzbein SD, Robbins SE. Accuracy of pedicular screw placement in vivo. Spine (Phila Pa 1976). 1990;15:11-4

16. Belmont PJ Jr, Klemme WR, Dhawan A, Polly DW Jr. In vivo aceuracy of thoracic pedicle screws. Spine (Phila Pa 1976). 2001;26:2340-6.

17. Suk SI, Lee CK, Kim WJ, Chung YJ, Park YB. Segmental pedicle screw fixation in the treatment of thoracic idiopathic scoliosis. Spine (Phila $\mathrm{Pa}$ 1976). 1995;20:1399-405.

18. Kim YJ, Bridwell KH, Lenke LG, Kim J, Cho SK. Proximal junctional kyphosis in adolescent idiopathic scoliosis following segmental posterior spinal instrumentation and fusion: minimum 5-year follow-up. Spine (Phila Pa 1976). 2005;30:2045-50.

19. Di Silvestre M, Bakaloudis G, Lolli F, Vommaro F, Martikos K, Parisini P. Posterior fusion only for thoracic adolescent idiopathic scoliosis of more than 80 degrees: pedicle screws versus hybrid instrumentation. Eur Spine J. 2008;17:1336-49.

20. Bago J, Climent JM, Ey A, Pérez-Grueso FJ, Izquierdo E. The Spānish version of the SRS-22 patient questionnaire for idiopathic scoliosis: transcultural adaptation and reliability analysis. Spine (Phila Pa 1976). 2004;29:1676-80.

21. Rosales-Olivarez LM, García J, Miramontes-Martínez VP, Alpízar-Aguirre A, Arenas-Sordo M de L, Reyes-Sánchez AA. Tratamiento quirúrgico de la escoliosis. Control de evolución mínimo de 5 años. Cir Cir. 2007;75:93-7. 